SECTION FOUR.

Possibilities of Applying AI-based LegalTech Tools in Legal Practice 


\section{AI and the Work of Lawyers in the Light of the Council of Europe Guidelines}

Marek Świerczyński

\section{Introduction}

The ambitious goal of AI-based technologies is to equip computers with the functions of the human mind, i.e. the ability to learn, recognize and reason. The ability to understand natural language and to think independently from humans is key to the further development of AI-based technologies ${ }^{1}$. AI-based systems perform increasingly complex and important tasks with reduced human control (or even no supervision at all). They can change initial algorithms by processing external data collected during their activity $^{2}$.

As long as machines act as mere executors of human will, their actions should be normatively attributed to a natural person. Although AI systems are often viewed as operating autonomously, they typically just support humans and automate routine tasks ${ }^{3}$. Once the individuals operating AI systems have been identified, the extent of their liability should be proportionate to the actual level of instruction given to the AI systems.

As in case of many other disruptive innovations, AI-based tools pose legal risks. They can be characterized by limited predictability. This phenomenon is intensifying with the rise of machine learning technologies and the development of quantum computers ${ }^{4}$. AI algorithms can be defec-

1 Habib Hadj-Mabrouk, 'Contribution of Artificial Intelligence to Risk Assessment of Railway Accidents‘ (2019) 5(2) Urban Rail Transit 107.

2 Expert Group on Liability and New Technologies New Technologies Formation, Liability for Artificial Intelligence and other emerging digital technologies, 'Report' (European Union 2019) 33, hereinafter as “AI Liability Report (2019)".

3 See further in the report: Center Information Policy Leadership 'Artificial Intelligence and Data Protection: Delivering Sustainable AI Accountability in Practice. First. Report: Artificial Intelligence and Data Protection in Tension' (2018) $6<$ https://www.informationpolicycentre.com/uploads/5/7/1/0/57104281/cipl_ai_fi rst_report_-_artificial_intelligence_and_data_protection_in_te....pdf $>$. accessed 8 April 2021.

4 AI Liability Report (2019) 43. 
tive. The data bases used for AI training may be inadequate or contain inaccurate data ${ }^{5}$. This could lead to decisions, predictions or analyses made by AI systems being undermined, cause harm and result in legal liability for certain individuals, including their users and manufacturers ${ }^{6}$. The negative aspects of AI tools are now widely recognized, including the "black box" problem (to be further explained in this chapter) ${ }^{7}$. For these reasons, lawyers therefore need clear guidelines for the use of AI tools in the judicial systems. Such guidelines have been already prepared by the Council of Europe.

\section{Definition of Artificial Intelligence}

Artificial intelligence lacks uniform legal definition. Diverse definitions are presented in international documents (EU, Council of Europe, OECD, UNESCO). However, adoption of a uniform legal definition is a key issue. When discussing the topic of artificial intelligence, we tacitly assume that we all understand this concept in the same way. In fact, the proposed definitions are far different ${ }^{8}$.

As a scientific discipline, AI encompasses a variety of approaches and techniques, such as machine learning (of which deep learning and reinforcement learning are specific examples), machine reasoning (involving planning, action programming, knowledge representation and reasoning, search, and optimization), and robotics (involving control, perception, sensors, and actuators, as well as the integration of all other techniques in cyber-physical systems). Since in this chapter we present the guidelines of the Council of Europe, it is necessary first to address the definition used for the purposes of this international organization. The AI definition can be found in the European Ethical Charter on the use of artificial intelligence in judicial systems and their environment, adopted by the European Commission CEPEJ ${ }^{9}$. It states that "artificial intelligence" or

5 See further Thomas H. Coormen, Algorithms Unlocked (MIT Press 2013).

6 Virginia Dignum, Responsible Artificial Intelligence, How to Develop and Use. AI in a Responsible Way (Springer 2019) 99.

7 Rosario Girasa, Artificial Intelligence as a Disruptive Technology. Economic Transformation and Government Regulation (Palgrave Macmillan 2020), 4.

8 Tomasz Zalewski 'Definicja sztucznej inteligencji' in Luigi Lai and Marek Świerczyński (eds), Prawo sztucznej inteligencji (C. H. Beck 2020).

9 See further European Ethical Charter on the use of artificial intelligence in judicial systems and their environment, Council of Europe, Commission for the Efficiency 
"AI" refers to a set of scientific methods, theories and techniques that aim to replicate human cognitive abilities by a machine. The Charter sets out 5 principles to which the development of AI tools in European judicial systems should be subjected. These 5 principles are also fully reflected in the 2021 Guidelines for Digitization of the Judiciary, which will be presented in the later section of this chapter.

The guidelines implement also the initial definition of AI proposed in the EC Communication on AI, subsequently expanded by the independent high-level expert group on AI that was convened by the $\mathrm{EC}^{10}$, as well as the definition of AI system in the OECD Council Recommendation on AI adopted in $2019^{11}$. The latter applies to AI systems and it states that: "An AI system is a device-based system that can, with respect to a specific set of human-defined goals, make predictions, recommendations, or decisions that affect real or virtual environments. AI systems are designed to operate with varying degrees of autonomy". As we see, both CoE and OECD definitions are simpler and clearer than the recent vague definition of the AI system presented by the EU in the draft regulation on AI (published on 21.04.2021).

\section{The "Black Box" Problem in AI Decision Making Process}

A key legal issue for practical applications of AI tools by the lawyers is the so-called "black box" problem ${ }^{12}$. This term refers to algorithms whose implementation and usage is opaque, and in result it is difficult to under-

of Justice (CEPEJ), <https://rm.coe.int/ethical-charter-en-for-publication-4-decemb er-2018/16808f699c > accessed 8 April 2021.

10 See further The European Commission's high-level expert group on artificial intelligence, 'A Definition of AI: Main Capabilities and Scientific Disciplines. Definition developed for the purpose of the deliverables of the High-Level Expert Group on AI Brussels': <https://ec.europa.eu/digital-single-market/en/news/defin ition-artificial-intelligence-main-capabilities-and-scientific-disciplines $>$ accessed 8 April 2021 and $<$ https://ec.europa.eu/digital-single-market/en/news/ethics-guideli nes-trustworthy-ai> accessed 8 April 2021.

11 Recommendation of the OECD Council on Artificial Intelligence, 'OECD/LEGAL/0449’ <https://legalinstruments.oecd.org/en/instruments/OECD-LEGAL-044 9> accessed 8 April 2021.

12 Se further Manuel Carabantes, 'Black-box artificial intelligence: an epistemological and critical analysis' (2019) 35 AI \& Society. 
stand the internal workings of the method ${ }^{13}$. The problem of explainability of decisions made with AI tools occupies a central place at the interface between AI and law. Explainability is an important legal category not only in respect to data protection law, but also in case of law of obligations. Contract and tort law (rather than data protection law itself) may impose legal requirements to use machine learning models that are capable of being explained ${ }^{14}$. Explainability has become a key consideration for AI tools from both a technical and legal perspective.

As an example, we can mention the use of AI tools in the justice system. When using complex algorithms leading to the effect of the so-called black box, it is impossible to analyse the decision-making process. This leads to the conclusion that the evaluation of cases submitted to the court, except those of a routine and formal nature, must be always carried out by a human judge. Otherwise, the civilizational and cultural foundation of the judiciary, which is the independence of the courts and the independence of judges, would be disturbed ${ }^{15}$.

Paragraph 41 of the conclusions of the Council of the European Union entitled: "Access to justice - seizing the opportunities of digitization" accurately points out that: "The results of the reasoning of artificial intelligence systems based on machine learning cannot be reproduced, leading to a black box effect that prevents proper and necessary accountability and makes it impossible to verify how the result was reached and whether it complies with the relevant rules. This lack of transparency can undermine the ability to effectively challenge decisions based on such results and thus violate the right to due process and an effective remedy, and limit the areas in which these systems can be legitimately used"16.

In this context the warning of the Council of European Judges (CJEU) present in Opinion No. 14 of 2011 remains valid. It states that: "the introduction of IT in courts in Europe should not endanger the human and symbolic face of justice. (...) Justice is and should remain human, because it is primarily about people and their disputes". Also, the EC points out

13 Andrzej Krasuski, Status prawny sztucznego agenta, Podstawy prawne zastosowania sztucznej inteligencji (C. H. Beck 2020) 153.

14 Philipp Hacker, Ralf Krestel, Stefan Grundmann, Felix Naumann, 'Explainable AI under contract and tort law: legal incentives and technical challenges' ${ }^{6}(2020)$ 28 Artificial Intelligence and Law, 416.

15 Aleksandra Partyk 'Legitim 2.0., czyli o robocie przyszłości... rozstrzygającym spory zachowkowe' (2019) 2(25) Studia Prawnicze 38.

16 https://sip.lex.pl/akty-prawne/dzienniki-UE/konkluzje-rady-dostep-do-wymiaru-s prawiedliwosci-wykorzystanie-mozliwosci-69365245> accessed 8 April 2021. 
in the AI White Paper that: "the specific characteristics of many AI technologies, including opacity ('black box effect'), complexity, unpredictability and partially autonomous behaviour, may make it difficult to verify compliance with the provisions of existing EU law aimed at protecting fundamental rights and impede their effective enforcement" ${ }^{17}$.

\section{Council of Europe Work on Artificial Intelligence}

The Council of Europe is currently playing a key role in ensuring that AI is developed in line with human rights protection standards. The organization supports also other international AI initiatives in this area, including those of the OECD, EU, UNESCO ${ }^{18}$. Cooperation is carried out in the direction of seeking synergies of activities and avoiding duplication of work. The Council of Europe's activities in the field of AI law are rich and varied $^{19}$. The resulting achievements can be divided into four areas:

1) Recommendations, guidelines and other instruments issued by Council of Europe bodies or established AI committees ${ }^{20}$;

2) Studies, reports and conclusions from key events (such as conferences and expert sessions) ${ }^{21}$;

17 European Commission, White Paper On Artificial Intelligence - A European approach to excellence and trust. , Brussels, COM (2020) 65 final, 12, <https://ec.e uropa.eu/info/sites/info/files/commission-white-paper-artificial-intelligence-feb202 0_en.pdfs.

18 See further: <https://www.oecd.org/going-digital/ai/> access 17 March 2021, $<$ https://ec.europa.eu/digital-single-market/en/artificial-intelligence > access 17 March 2021; and <https://en.unesco.org/artificial-intelligence> access 17 March 2021.

19 See further: <https:/www.coe.int/en/web/artificial-intelligence/work-in-progress> access 17 March 2021.

20 Recommendation of the Committee of Ministers to member States on the human rights impacts of algorithmic systems, Recommendation on developing and promoting digital citizenship education, Declaration of the Committee of Ministers on the manipulative capabilities of algorithmic processes, European Ethical Charter on the use of artificial intelligence (AI) in judicial systems and their environment, Recommendation of the Parliamentary Assembly of the Council of Europe about Technological convergence, artificial intelligence and human rights, $<$ https://search.coe.int/cm/pages/result_details.aspx?objectid=09000016809e 1154> (accessed 8 September 2021).

21 Such as: Feasibility study on the establishment of a certification mechanism for artificial intelligence tools and services (2020); Artificial intelligence in the audiovisual industry - Summary of the workshop (2019); Artificial intelligence and its 
3) Reports of the Parliamentary Assembly of the Council of Europe 22;

4) Other initiatives ${ }^{23}$.

The importance of the work on AI is highlighted by the creation withing the Council of Europe of the Ad hoc Committee on Artificial Intelligence (CAHAI $)^{24}$. CAHAI aims to analyse, on the basis of broad consultation and collaboration with different stakeholders, the issue of possible global regulation of artificial intelligence (AI) on the basis of the Council of Europe's promoted standards for human rights, democracy and the rule of $\mathrm{law}^{25}$.

impact on young people - Seminar report (2019); Proceedings of the Roundtable on Artificial Intelligence and the Future of democracy (2019) CDDG-Bu(2019, 17),; Conclusions from the Conference "Governing the Game Changer - Impacts of artificial intelligence development on human rights, democracy and the rule of law" (2019).

22 Such as the following reports: artificial intelligence and labour markets: friend or foe?; Report on Artificial intelligence in health care: medical, legal and ethical challenges ahead; Report on Justice by algorithm (the role of artificial intelligence in policing and criminal justice systems); Report on preventing discrimination caused by the use of artificial intelligence; Report on the need for democratic governance of artificial intelligence.

23 Concept note: Artificial intelligence and criminal law responsibility in Council of Europe member states - the case of automated vehicles, Development of Recommendation and Study on the impacts of digital technologies on freedom of expression, Youth policy standards and other institutional responses to newly emergent issues affecting young people's rights and transition to adulthood, including AI, Report on AI in the audiovisual industry, Draft Declaration of the Committee of Ministers of the Council of Europe on the risks of computer-assisted or artificial-intelligence-enabled decision making in the field of the social safety net.

24 See <https://rm.coe.int/cahai-2020-2021-rev-en-pdf/16809fc157> accessed 17 March 2021.

25 The CAHAI is composed of representatives of the 47 member states, appointed by their governments, who have recognized expertise in digital governance and the legal implications of various forms of AI; representatives of observer states (such as Canada, Vatican, Israel, Japan, Mexico, USA); representatives of other Council of Europe bodies, in particular the Secretariat of the Parliamentary Assembly, the Office of the Commissioner for Human Rights, and intergovernmental commissions dealing with AI issues. Human Rights, and intergovernmental commissions dealing with AI issues; representatives of other international and regional organizations working in the field of artificial intelligence, such as the EU, the UN (in particular UNESCO), OECD, OSCE; representatives of the private sector, including companies and associations with which the Council of Europe has exchanged letters in the framework of its partnership with digital enterprises; representatives of civil society, research and academic institutions who have been 
One may well ask what justification there is for the Council of Europe to undertake legislative work fundamental to the international legal order on the use of AI in the legal sector. It is undoubtedly an experienced international organization that has acted quickly and efficiently in the past and provided strong legal reaction to disturbing new technologies. The Data Protection Convention No. 108 and the Cybercrime Convention created by the Council of Europe set global standards for legal protection. Through the European Convention on Human Rights and other legal instruments, the Council of Europe is in a strong position to define the international legal framework for artificial intelligence ${ }^{26}$. It was also the Council of Europe that was the first international organization to create a legal framework for biomedicines. To this day, the Oviedo Convention ${ }^{27}$, opened for signature in 1997, remains the only binding international legal instrument for the protection of human rights in the field of biomedicine. It incorporates the principles provided for in the European Convention on Human Rights. The same assumptions based on the protection of human rights should be applied to the use of artificial intelligence technologies in legal systems ${ }^{28}$. AI tools should not be introduced without establishing clear international rules to protect against the risk of discrimination, privacy or security breaches, establishing clear liability rules and key legal aspects $^{29}$.

admitted by CAHAI as observers; see further: <https://www.coe.int/en/web/artific ial-intelligence/cahai\#\{\%2266693418\%22:[0]\}> access 17 March 2021 and $<$ https:// rm.coe.int/list-of-cahai-members-web/16809e7f8d > accessed 17 March 2021.

26 Human Rights in the Era of AI - Europe as international Standard Setter for Artificial Intelligence, Conference Conclusions: $<$ https://www.coe.int/en/web/arti ficial-intelligence/human-rights-in-the-era-of-ai> accessed 17 March 2021.

27 The Convention for the Protection of Human Rights and Dignity of the Human Being with regard to the Application of Biology and Medicine: Convention on Human Rights and Biomedicine (ETS No 164), open for signature on 4.4.1997 r. in Oviedo (Spain).

28 Filippo A. Raso. Hannah Hilligoss. Vivek Krishnamurthy. Christopher Bavitz, 'Artificial Intelligence \& Human Rights: Opportunities \& Risks, Berkman Klein Center for Internet \& Society' (Harvard University 2018) 6, <https://papers.s srn.com/sol3/papers.cfm?abstract_id=3259344> accessed 17 March 2021.

29 See further Karen Yeung, A study of the implications of advanced digital technologies (including AI systems) for the concept of responsibility within a human rights framework, <https://rm.coe.int/a-study-of-the-implications-of-advanced-digi tal-technologies-including/168096bdab $>$ accessed 17 March 2021. 


\section{Council of Europe Guidelines on Common Courts Digitalisation}

The most recent document developed by the Council of Europe are the guidelines on the online dispute resolution (ODR) mechanisms that aim to ensure compatibility with Article 6 (right to a fair trial) and Article 13 (right to an effective remedy) of the European Convention on Human Rights (ECHR). They have been prepared by the CDCJ (European Committee for Legal Affairs) of the Council of Europe. The guidelines were completed on 24.11.2020 and are to be adopted by the Committee of Ministers of the Council of Europe on May 2021. The guidelines set the current standard of documents regulating the digitization of justice. They also provide a model for further soft - law instruments, to be prepared by the Council of Europe.

A comprehensive background to the guidelines on the use of AI tools in the justice sector emerges from the official commentary (Explanatory Memorandum) to the guidelines. It indicates that the introduction of AI tools into civil and administrative proceedings enables automated decision-making ${ }^{30}$. It also leads to faster proceedings and allows for more predictable and fairer outcomes ${ }^{31}$. Moreover, many states are already using AI tools to anonymize court decisions or translate documents and plan to use them more extensively in judicial proceedings (e.g in the remote hearings). New AI tools can assist judges in other activities, such as advanced data analytics, among others ${ }^{32}$. In some states, the possible replacement of the judge (human) with an information system for data processing and analysis is being considered ${ }^{33}$. In result the increasing use of AI tools in the courts should be addressed in basic procedural rules ${ }^{34}$. This is the subject of current work of the Council of Europe bodies, such as CDCJ.

The guidelines in question address various problems of using AI tools by the courts.

30 Davide Carneiro, Paulo Novais, Francisco Andrade, John Zeleznikow and José Neves, 'ODR: an Artificial Intelligence Perspective' (2014) 41 Artificial Intelligence Review, 211-240.

31 Maxi Scherer, 'Artificial Intelligence and Legal Decision-Making: The Wide Open?‘ (2019) 36 Journal of International Arbitration, No. 5, 539 - 574.

32 Sofia Samoili and others, 'AI Watch. Defining Artificial Intelligence. Towards an operational definition and taxonomy of artificial intelligence, EUR 30117 EN, Publications Office of the European Union' (2020), 7-8.

33 Jacek Gołaczyński, ‘e-Sąd przyszłości' (2019) 2 Monitor Prawniczy, 97.

34 See further Ephraim Nissan, 'Digital technologies and artificial intelligence's present and foreseeable impact on lawyering, judging, policing and law enforcement' (2017) 32 AI \& Society, 539 - 574. 
Firstly, parties should be notified of the intention to process their case using an AI tool (Guideline 6). Parties to proceedings have the right to be informed about the AI-based processing operations that are applied. This information also includes the consequences of the AI tool being used $^{35}$. This is a transparency requirement that is formulated by numerous international organizations. It is stipulated in the recommendations, codes of ethics and guidelines that establish ethical standards for the design, use and application of artificial intelligence, enacted by Council of Europe, $\mathrm{UN}, \mathrm{EU}, \mathrm{OECD}$ and other international institutions. These standards must be adhered to by designers and suppliers as well as administrators of AI systems for their use in the courts.

Secondly, Guideline No. 18 requires that sufficient justification must be provided to the parties of the court proceedings for court decisions based on digital tools, such as AI systems. The wording of the guideline means that the Council of Europe does not oppose the use of artificial intelligence in the judicial decision making. The purpose of the guideline is to set limits on its use in accordance with principles under the ECHR and other human rights instruments. This guideline is intended to promote transparent judicial decision-making. Decisions that make it impossible to see how a result was achieved are as much a threat to transparency and the principle of due process as decisions that do not contain a statement of reasons at all $^{36}$. Parties are entitled to an explanation of the processing operations applied to them. This should include the consequences of such reasoning. If, due to the nature of the AI tool used, no information can be provided (i.e. "black box" problem), courts should refrain from issuing decisions made with AI whose reasoning results cannot be reproduced.

Thirdly, Guideline No. 20 provides for the right to review adjudications based on AI tools. This issue was particularly controversial during the travaux preparatoires of the guideline. This is because the wording of this guideline suggests that the Council of Europe permits member states to replace human judge with the AI system. One can ask if this is in line with the ECHR? In the case of EU, the authorities already issued resolutions opposing fully automated decision-making in the judiciary. In the previously quoted conclusions of the Council of the European Union we read

35 Jenna Burrell, 'How the Machine 'Thinks': Understanding Opacity in Machine Learning Algorithms، (2016), 3(1) Big Data \& Society, <https://papers.ssrn.com/so 13/papers.cfm?abstract_id=2660674 $>$ accessed 8 September 2021.

36 Wojciech Samek, Thomas Wiegand and Klaus-Robert Müller, 'Explainable Artificial Intelligence: Understanding, Visualizing and Interpreting Deep Learning Models' (2017), 1 ITU Journal: ICT Discoveries, 1 - 10. 
that: "the use of artificial intelligence tools must not interfere with the decision-making powers of judges or the independence of the courts. The decision of the court must always be made by a human being and must not be delegated to an artificial intelligence tool.". We see that Council of Europe adopt more flexible approach in this respect.

\section{Summary and Conclusions}

The Council of Europe guidelines address the current needs of lawyers resulting from the use of $\mathrm{AI}$ tools in their judicial practice ${ }^{37}$. The condition for the proper development of AI tools in the legal system is directly linked to effective processing of data and digitalisation of documents ${ }^{38}$. When it comes to court proceedings, it is important to give clear instruction to what extent AI tools can be used in court practice, including the replacement of the judge. Such solution requires a detailed legal analysis whether in such a case we would still be dealing with a court within the meaning of the ECHR.

The Council of Europe guidelines relating to artificial intelligence, as an instrument of so-called soft law, are suitable for easy changes and additions as technology advances. The Council of Europe Strategy for future was presented at the Council of Europe Conference of 20.1.2021. Its main purpose was to present the work to date of CAHAI (the ad hoc committee on artificial intelligence), which is preparing principles of global legal framework for artificial intelligence. The feasibility study conducted by CAHAI identifies gaps in the current legal framework with respect to the challenges associated with the design, development and use of artificial intelligence. It also concludes that limiting the Council of Europe's future work to soft - law instruments is not sufficient due to the excessive limitations of this method of regulation. Thus, it seems that the adoption of an international Council of Europe convention on artificial intelligence is only a matter of time.

The claim that legal regulation of artificial intelligence hinders the progress of innovation is wrong. The exact opposite is true. Clear, sensible and risk-management based regulation provides legal certainty ${ }^{39}$. National

37 Gołaczyński (n 33) 98.

38 ibid.

39 See the speech of Christian Kastrop during the CoE conference 'Human Rights in the Era of AI - Europe as International Standard Setter for Artificial Intelligence' 
regulation is not sufficient. Technologies based on artificial intelligence are global in nature. Therefore, multilateral cooperation among countries is needed to establish uniform international standards and the Council of Europe is in the best position to create such standards.

(2021), <https:/www.coe.int/en/web/artificial-intelligence/human-rights-in-the-er a-of-ai> accessed 17 March 2021. 
